\title{
OS TERRITÓRIOS INDIGENAS NAS FONTES ESCRITAS: DIÁLOGO ENTRE HISTÓRIA E ANTROPOLOGIA.
}

Lenir Gomes Ximenes

Doutora em História pela Universidade Federal da Grande Dourados. Docente da Universidade Católica Dom Bosco. Colaboradora do Núcleo de Estudos e Pesquisas das Populações Indígenas

(NEPPI/UCDB).

lenir_gximenes@hotmail.com

\section{Hélita da Silva Igrez Branco}

Administradora, graduanda em História pela Universidade Católica Dom Bosco. Integrante do Núcleo de Estudos e Pesquisas das Populações Indígenas (NEPPI/UCDB). helita_igrez@hotmail.com

$\&$

Mabel Saldanha Shinohara

Bacharel em Comunicação Social, graduanda em História pela Universidade Católica Dom Bosco. Integrante do Núcleo de Estudos e Pesquisas das Populações Indígenas (NEPPI/UCDB). mabelss.cedoc@gmail.com

resumo: O diálogo interdisciplinar entre História e Antropologia é fundamental para a escrita de uma História que reconheça os indígenas como sujeitos históricos plenos. As fontes escritas inserem-se nesse contexto como importantes materiais de trabalho para os pesquisadores, juntamente com outros tipos de fonte: orais, imagéticas, audiovisuais e provenientes da cultura material. 0 presente artigo é resultado das reflexões desenvolvidas no âmbito do projeto de extensão "Cedoc: preservação do patrimônio histórico e cultural indígena no MS", desenvolvido no Centro de Documentação Indígena Teko Arandu - Cedoc, no Núcleo de Estudos e Pesquisas das Populações Indígenas - NEPPI/UCDB. O objetivo é demonstrar as possibilidades de utilização de documentos oficiais e de materiais da imprensa nas pesquisas acerca das terras indígenas e das mobilizações em torno da retomada pelos indígenas dos seus territórios tradicionais.

Palauras-chave: História Indígena; território indígena; documentação histórica. abstract: The interdisciplinary dialogue between History and Anthropology is fundamental to the writing of a History that recognizes the indigenous people as full historic subjects. The written sources are inserted in this context as important work materials to researchers, together with other kinds of source: oral, imagetics, audiovisual, and originating from material culture. The present article is the result of reflections developed within the framework of the extension project "Cedoc: preservação do patrimônio histórico e cultural indígena no MS", developed in the Centro de Documentação Indígena Teko Arandu - Cedoc, in the Núcleo de Estudos e Pesquisas das Populações Indígenas - NEPPI/UCDB. The goal is to demonstrate the possibilities of the usage of official documentation and of press material in the researches regarding indigenous lands and the mobilization around indigenous regaining control of their traditional territories.

Key-words: Indigenous History; indigenous territory; historic documentation. 


\section{introdução}

(e)

diálogo entre História e Antropologia é fundamental para a escrita de "uma nova história indígena", como pontua John Monteiro, ao referir-se aos trabalhos que reconhecem os indígenas como sujeitos históricos plenos, como protagonistas da História. João Pacheco Oliveira Fillho, também contríbui com essa discussão ao destacar que tanto historiadores quanto antropólogos lidam com processos socioculturais que se desenvolvem no tempo e que o "pesquisador precisa resgatar a plena historicidade dos sujeitos históricos, descrever como eles estão imersos e como se constituem em cada ambiente líquido (as épocas e os ecúmenos)"?

No âmbito do trabalho de historiadores e antropólogos, é fundamental a reflexão sobre as fontes utilizadas tanto em pesquisas acadêmicas, quanto na elaboração de laudos de reconhecimento de terras de ocupação tradicional indígena. As fontes escritas inserem-se nesse contexto como importantes materiais de trabalho para os pesquisadores dessas duas áreas, juntamente com outros tipos de fonte: orais, imagéticas, audiovisuais e provenientes da cultura material.

$\bigcirc$ presente artigo é resultado das reflexões desenvolvidas no âmbito do projeto de extensão "Cedoc: preservação do patrimônio histórico e cultural indígena no MS", desenvolvido no Centro de Documentação Indígena Teko Arandu - Cedoc, no Núcleo de Estudos e Pesquisas das Populações Indígenas - NEPPI/UCDB. O objetivo é demonstrar as possibililidades de utilização de documentos oficiais e de materiais da imprensa nas pesquisas acerca das terras indígenas e das mobilizações em torno da retomada pelos indígenas dos seus territórios tradicionais.

\footnotetext{
${ }^{1}$ MONTEIRO, John Manuel. Armas e armadilhas: história e resistência dos índios. In: NOVAES, Adauto (org.). A outra margem do Ocidente. São Paulo, Companhia das Letras, 1999.
}

2 OLIVEIRA FILHO, João Pacheco. Ensaios em Antropologia histórica. Rio de Janeiro: UFRJ, 1999, p. 106. 
Em relação aos documentos oficiais, o artigo aborda a documentação do Serviço de Proteção aos Índios - SPI e o Relatório Figueiredo, material da década de 1960, que trata de inúmeras violações de direito cometidas contra os povos indígenas no período de atuação do SPI. Em relação aos materiais da imprensa foram analisadas matérias de jornal do acervo do Cedoc, que abordam reivindicações territoriais. $\bigcirc$ foco do presente texto são os povos indígenas no Mato Grosso do Sul.

\section{o centro de documentação indígena teko arandu - cedoc}

$\bigcirc$ Centro de Documentação Indígena Teko Arandu - Cedoc, faz parte do Núcleo de Estudos e Pesquisas das Populações Indígenas - NEPPI O NEPPI é um órgão de natureza executiva, criado na Universidade Católica Dom Bosco - UCDB, em Campo Grande, no ano de 1995, congregando atividades de pesquisa e extensão direcionadas às populações indígenas, em especial, às que habitam o Mato Grosso do Sul. Em 1997, foi criado no NEPPI o Cedoc, com materiais e documentos sobre os grupos Guarani. Posteriormente o acervo foi ampliado com coleções documentais e bibliográficas que abrangem outras etnias indígenas no estado.

Desde 2000, o Cedoc está aberto ao público e dispõe de um vasto acervo composto por documentos oficiais dentre os quais se destacam: 1) Documentos que datam do século XVIII, referentes à Capitania do Mato Grosso, que abrangia o território do atual Mato Grosso do Sul, ocupado por diversos grupos indígenas. Esses materiais são cópias digitalizadas disponibilizadas pelo Arquivo Histórico Ultramarino, de Portugal. 2) Documentos do SPI, órgão indigenista que funcionou de 1910 a 1967. Essa coleção é composta por 58 rolos de microfilmes (de 35 mm, cada um com cerca de 5 mil fotogramas) que são cópias adquiridas do Museu do Índio.

$\bigcirc$ acervo também dispõe de rico material bíbliográfico (livros, teses, dissertações, revistas científicas), fotografias, mapas, jornais, fitas K7, fitas VHS, CDs e DVDs com mais de 260 horas de gravação de entrevistas com representantes indígenas de mais idade, alguns inclusive já falecidos. Em relação aos materiais da imprensa, o Cedoc possui cerca de 5 mil reportagens e artigos a respeito da temática indígena, provenientes de jornais impressos locais e nacionais, divididos em temas como: aldeias, cultura, educação, violência e território. Parte do acervo está catalogado e descrito em um sistema próprio no site www.neppiorg.

Diversos projetos de extensão e pesquisa já foram desenvolvidos no referido Centro, fomentando não somente a salvaguarda e a catalogação dos materiais, mas também a produção acadêmica, especialmente na área da História. $\bigcirc$ projeto de extensão "Cedoc: preservação do patrimônio histórico e cultural indígena no MS", 
desenvolvido desde o ano de 2014, tem suscitado reflexões acerca da temática indígena nos documentos oficiais e nos materiais da imprensa, tanto a partír de materiais disponíveis no Cedoc, quanto a partir de materiais disponíveis em acervos virtuais, a exemplo do Relatório Figueiredo, disponíbilizado no site do Museu do Indio.

\section{os territórios indígenas e os documentos oficiais}

Carlos Bacellar destaca que a relação dos historiadores com as fontes documentais se alterou ao longo do tempo, perpassando desde os "que viam nos documentos fontes de verdade, testemunhos neutros do passado" até os que "analisam seus discursos, reconhecem seus vieses, desconstroem seu conteúdo, contextualizam suas visões" 3. A partir dessa nova postura em relação às fontes escritas, sobretudo em relação àquelas produzidas pelo Estado, foi possível romper com a inviabilidade dos povos indígenas na historiografia.

Em relação às diferentes formas de resistência indígena, por exemplo, John Monteiro destaca que, apesar de negligenciado, esse tema não é novo na História, pelo contrário, remonta aos escritos coloniais. $\bigcirc$ que se renova em relação à historiografia tradicional é a abordagem, que atualmente reconhece os indígenas como sujeitos históricos. ${ }^{4}$

Documentos produzidos em um contexto desfavorável à manutenção dos territórios indígenas (até a década de 1980) podem embasar as reivindicações atuais desses povos na recuperação de suas terras tradicionais. Dessa forma, a documentação do SPI, órgão indigenista que atuou até 1967, pode elucidar várias questões a respeito da remoção forçada de grupos indígenas e das pressões de proprietários rurais e até do próprio órgão para líberação de áreas indígenas para a formação de propriedades particulares.

[No acervo do SPI] há relatórios, ofícios, memorandos e outras correspondências oficiais sem periodicidade estabelecida, abordando questões como extensão territorial das áreas indígenas e o desrespeito aos seus limites pelos regionais, bem como a retirada de famílias indígenas de determinados locais e sua

\footnotetext{
3 BACELLAR, Carlos. Fontes documentais. Uso e mau uso dos arquivos. PINSKY, Carla Bassanezi (org.). Fontes históricas. São Paulo: Contexto, 2005, p. 25.
}

${ }^{4}$ MONTEIRO, John Manuel. Armas e armadilhas. Op. cit. 
transferência para áreas reservadas pelo SPI, como forma de liberar terras para requerentes não indígenas.

Em relação aos Terena, por exemplo, Vera Lúcia Ferreira Vargas ressaltou que a documentação do SPI e da Eundação Nacional do Índio - EUNAI, forneceram dados históricos "que permitiram visualizar um contexto geral da história da sociedade Terena e também indicaram os mecanismos usados por eles ao longo de sua história, principalmente para a legalização de suas terras, evidenciando sua condição de sujeitos históricos"6

A interdisciplinaridade é elemento fundamental na leitura das fontes escritas a respeito da temática indígena, especialmente o já mencionado diálogo entre História e Antropologia. $\bigcirc$ cruzamento com relatos orais e com a etnografia constitui campo fértil para a análise das fontes documentais. Isso pode ser percebido não só nas pesquisas de caráter acadêmico, mas também nos relatórios resultantes de perícias de reconhecimento de terras indígenas, como demonstra o texto de Jorge Eremites de Oliveira e Levi Marques Pereira?

Além dos materiais do próprio SPI, o Relatório Figueiredo, um documento da década de 1960, é uma fonte importante e ainda pouco explorada para a discussão acerca dos direitos indígenas. Concluído no início da Dítadura Militar (1964-1985), o Relatório registra diversas atrocidades cometidas contra indígenas de todo país, incluindo torturas e mortes. $\bigcirc$ documento ficou desaparecido por décadas e teria supostamente sido queimado em um incêndio no Ministério da Agricultura, entretanto, reapareceu em 2013. O Relatório foi analisado durante os trabalhos da Comissão Nacional da Verdade - CNV, pelo Grupo de Trabalho sobre violações de direitos humanos, praticadas por motivação política, relacionadas à luta pela terra ou contra os povos indígenas, no período de 1946 a $1988^{8}$.

${ }^{5}$ FERREIRA, Eva Maria Luiz; XIMENES, Lenir Gomes. Os documentos do SPI como fontes para a História Indígena. Tellus. Ano 16, n. ${ }^{\circ}$ 30, jan./jun. 2016, p. 158.

${ }^{6}$ VARGAS, Vera Lúcia Ferreira. A dimensão sociopolítica do território para os Terena: as aldeias nos séculos XX e XXI. 2011. 188 f. Tese (Doutorado em História), Universidade Federal Fluminense, Rio de Janeiro, 2011, p. 19.

7 EREMITES DE OLIVEIRA, Jorge; PEREIRA, Levi Marques. Terra Indígena Buriti: perícia antropológica, arqueológica e histórica sobre uma terra terena na Serra de Maracaju. Dourados: UFGD, 2012.

${ }^{8}$ A Comissão Nacional da Verdade - CNV foi instituída em 2011, com o objetivo de averiguar as violações de direitos humanos praticadas durante a Ditadura Militar. Estabeleceu-se como recorte temporal o período que abrange da promulgação da Constituição Federal de 1946 à promulgação da Constituição Federal de 1988. No ano de 2012 foi instaurado, no âmbito da CNV, o Grupo de Trabalho sobre violações de direitos humanos, praticadas por motivação política, relacionadas à luta pela terra ou contra os povos indígenas. 
documento foi escrito por Jader de Figueiredo Correia, nesse período procurador-geral que presidia uma Comissão de Investigação do Ministério do Interior. Com ajuda de uma equipe, Jader visitou mais de 130 postos indígenas em todo país, em mais de 16 mil quilômetros percorridos. ${ }^{9} 10$

Relatório Figueiredo traz evidências da crueldade e das atrocidades cometidas contra indígenas, incluindo assassinatos de aldeias inteiras, no período de vigência do SPI Alguns desses crimes foram cometidos com a conivência ou negligência de agentes do Estado.11

Com a Comissão de Investigação e a conclusão do Relatório, em 1968, foram recomendadas as demissões de 33 pessoas do SPI e a suspensão de 17, no entanto, muitas delas foram inocentadas, como aponta Felipe Cânedo. ${ }^{12}$ Foi referido no documento que "a primeira comissão apontou, de início, a geral corrupção e a anarquia total imperantes no SPI em toda a sua área como, também, através dos tempos."13 Dentre as motivações das violações cometidas contra os indígenas, estavam os interesses nos territórios ocupados por esses povos.

Elena Guimarães aponta que quando divulgado, ainda no âmbito da Ditadura Militar, o Relatório causou tal impacto que despertou o olhar da imprensa (inclusive internacional, como o jornal The New York Tímes) e da opinião pública. Entretanto, a repercussão do documento, a extinção do SPI e sua substituiç̧ão pela EUNAI, não resultaram em uma política de reparação dos danos causados a esses povos. ${ }^{14}$ Só recentemente as questões levantadas pelo Relatório voltaram ao debate público, em parte pelas discussões da CNV. Iára Quelho de Castro e Vera Lucia Ferreira Vargas salientam que:

\footnotetext{
${ }^{9}$ CANÊDO, Felipe. Documento que registra extermínio de índios é resgatado após décadas desaparecido. In: EM Digital, 19 de abril de 2013.2 Disponível em: <http://www.em.com.br/app/noticia/politica/2013/04/19/interna_politica,373440/documento-queregistraexterminio-de-indios-e-resgatado-apos-decadas-desaparecido.shtml>. Acesso em: 02 mar. 2017.
}

${ }^{10}$ GUIMARÃES, Elena. Relatório Figueiredo: entre tempos, narrativas e memórias. 2015. 203f. Dissertação (Mestrado em Memória Social), Universidade Federal do Rio de Janeiro, Rio de Janeiro, 2015.

11 RELATÓRIO FIGUEIREDO. Comissão Parlamentar de Inquério para apurar irregularidades no Serviço de Proteção aos índios - SPI, instituída pela Portaria n. ${ }^{\circ}$ 239/1968. Arquivo Relatório Figueiredo/Museu do Î́ndio. Disponível em: <http://www.docvirt.com/docreader.net/DocReader.aspx?bib=museudoindio\&pagfis=>. Acesso em: 02 set. 2017.

12 CÂNEDO, 2013.

13 RELATÓRIO FIGUEIREDO, 1968, v. 20, p. 376.

${ }^{14}$ GUIMARÃES, 2015. 


\section{4}

[...] a violência contra os povos indígenas no Brasil constitui uma prática estatal (colonial e nacional) recorrente, não sendo prerrogativa de determinados períodos da história desta nação, constatando-se que não obstante as garantias legais, o desrespeito a essas persiste e é flagrante. ${ }^{15}$

Nesse sentido, apesar da Ditadura Militar ter acabado em 1985, os povos indígenas do Brasil seguem com diversos direitos sendo violados, inclusive o direito ao território, o que resulta em inúmeras outras violações. No ano de 2014, durante a realização de audiências públicas sobre a Violação de Direitos Indígenas no período de 1946-1988, os indígenas de diversas etnias de Mato Grosso do Sul "manifestaram seu descontentamento pelo recorte temporal abrangido pela CNV, argumentando que sofreram violações de direito antes de 1946 e que continuam sendo alvo de diversas violências e desrespeito aos seus direitos garantidos na Constituição Federal de 1988"16

Ressalta-se que além das violências físicas, o Relatório Figueiredo evidenciou roubos de patrimônio indígena, das riquezas (madeiras, gado, minérios e outros), como aponta o fragmento a seguir:

A crueldade para com o indígena só era suplantada pela ganância. No primeiro caso nem todos incorreram nos delítos de maus tratos aos índios, mas raros escaparam dos crimes de desvio e apropriação ou de dilapidação do patrimônio indígena. ${ }^{17}$

Os crimes cometidos contra indígenas incluem ainda trabalho compulsório, análogo à escravidão. Na maioria das vezes a origem dos problemas remonta às questões territoriais, ou seja, aos conflitos com latifundiários e aos interesses dos não índios nas terras ocupadas pelos indígenas. Nas investigações feitas entre 1963

${ }^{15}$ CASTRO, lára Quelho de; VARGAS, Vera Lúcia Ferreira. Povos indígenas e políticas estatais autoritárias no Brasil. In.: MARTINS JÚNIOR, Carlos; SOTANA, Edvaldo Correa; SOUSA NETO, Miguel Rodrigues (orgs.). Democracias e ditaduras no mundo contemporâneo. Campo Grande: UFMS, 2015, p. 98.

${ }^{16}$ XIMENES, Lenir Gomes. A Retomada terena em Mato Grosso do Sul: oscilação pendular entre os tempos e espaços da acomodação em reservas, promoção da invisibilidade étnica e despertar guerreiro. 2017. 289 f. Tese (Doutorado em História) - Universidade Federal da Grande Dourados, Dourados, 2017, p. 136.

${ }^{17}$ RELATÓRIO FIGUEIREDO, 1968, v. 20, p. 379. 
e 1967 são frisadas inúmeras irregularidades, com destaque para as apropriações de territórios indígenas. ${ }^{18}$

Diversas etnias são citadas no Relatório. Destacamos neste texto grupos que vivem no território do sul do antigo Mato Grosso, atual Mato Grosso do Sul, dentre eles os Kaiowá, Terena e Kadiwéu.

Em um boletim interno do SPI, de 1962, (arrolado no Relatório Figueiredo), foi registrado que a 5을 Inetoria Regional do SPI, que atendia o sul do Mato Grosso solicitou verbas para regularização de áreas dos Kaiowá no município de Dourados:

\begin{abstract}
A 5a Inspetoria se pronunciou a respeito, dizendo não abrir mão desta verba, pois a sua inspetoria tem sérios problemas em Dourados, Posto Francisco Horta e Panambi. Houve debate nesse ponto, pois que a lei orçamentária não prevê numerário para atendimento de demarcação de terras na $5^{a}$ Inspetoria. $\bigcirc$ senhor diretor, para deixar bem clara essa situação, disse que o emprego das verbas seria apenas nas Inspetorias constantes na Lei orçamentária, ou seja, as 2a $3^{a}$ e $6^{a}$ Inspetorias Regionais. A 5a Inspetoria ficou excluída. ${ }^{19}$
\end{abstract}

Como pode ser percebido, a verba não foí concedida e os problemas na região citada continuaram existindo, sendo tema de outros documentos do Relatório Figueiredo. No mesmo boletim há menções aos arredamentos de terra em área Kadiwéu, prática ora combatida, ora incentivada pelo órgão indigenista: "a 5a Inspetoria informou que, só no Posto Indígena Nalique há 61 arrendatários que têm contratos e pagam arredamentos e 76 que não têm contratos e pagam arrendamentos" 20

Um documento de autoria do funcionário Hélio Jorge Bucker, presente no Relatório Figueiredo, evidencia essas e outras irregularidades no Mato Grosso, especialmente em relação às terras indígenas. De acordo com ele, em alguns casos, os funcionários do SPI que tentavam garantir a posse dos indígenas sobre seus territórios, enfrentavam obstáculos colocados pelos interesses de outros agentes

\footnotetext{
18 Ibidem.

${ }^{19}$ COELHO, Moacyr Ribeiro. Boletim Interno do SPI n 57. Meses de set. - out. -nov. - dez. - 1962. In.: RELATÓRIO FIGUEIREDO, 1968, v. 6, p. 49.
}

20 Ibidem, p. 50. 
públicos, ligados aos poderes executivo e legislativo. Em outros casos, o próprio SPI teria agido de forma a lesar os indígenas. ${ }^{21}$ Em relação aos Kadiwéu, Bucker destaca:

No sul do Estado do Mato Grosso, além de outros tantos escândalos de tomada de terras indígenas, um se projetou até o Supremo Tribunal Federal. A desfaçatez dos políticos corruptos, foi tamanha que obtiveram através de Assembleia Estadual, a totalidade das terras dos Índios "Kadiuéo", sob a alegação de que para êles era muita terra (o grifo é meu). A lei espoliativa foi aprovada e no dia seguinte em um só número do Diário Oficial do Estado na totalidade de suas páginas estavam transcritos os requerimentos de familiares dos senhores Deputados, amigos e correligionários, todos candidatos a proprietários das terras dos Kadiuéo. Não fora o mandato de segurança impretado pelo SPI, o grande patrimônio dos índios Kadiuéo estaria hoje em outras mãos. Mas, aí não foi estabelecido o paradeiro do processo de tomada destas terras. Enquanto se arrastava pela justiça o mandato, os requerentes das terras colocaram nelas seus prepostos ocupando-as. Em seguida obtiveram através do Ministério da Agricultura (sob alegação de: ordem social e aumento de produção), que essas terras lhes fossem arrendadas sobre contrato por 8 (oito) anos e a baixo preço. Adveio assim, a cobiçada "Renda Indígena" da 5 a Inspetoria do SPI, que propositalmente os próprios arrendatários alardeiam a sua malversação, com o objetivo preconcebido - desmoralização da administração do SPI, e assenhoreamento definitivo da área.2

Em relação à área Kaiowá denominada Panambi, o mesmo relatório pontua:

Dos esbulhos de terras indígenas que tenho conhecimento nestes 18 anos, nenhum foi mais estranho e chocante do que o procedido diretamente pelo Ministério da Agricultura, atravez de seu Departamento de Terras e Colonização. Em 1943, esse departamento, distribuiu a título de colonização, as terras dos índios Kaiuá, inclusive a sua aldeia denominada "Panambi", no município de

${ }^{21}$ BUCKER, Hélio Jorge. Denúncia. Campo Grande, 1967. In.: RELATÓRIO FIGUEIREDO, 1968, v. 16, p. 187 196.

22 Ibidem, p. 195. 
Dourados - MT. É de estarrecer. $\bigcirc$ próprio órgão responsável pela garantia da terra do índio, é o primeiro a despoja-lo. ${ }^{23}$

Acerca do problema dos arrendamentos nas terras dos Kadiwéu, há várias outras menções ao longo do Relatório Figueiredo, como o fragmento transcrito a seguir:

Os Kadiuéus (antigos Guaicurús), donos das ricas terras que lhes deu o senhor D. Pedro II pela decisiva ajuda á tropas brasileiras naquela região durante a Guerra do Paraguai, sentem-se escorraçados em seus domínios, e seu gado vendido e suas mulheres prostituídas. ${ }^{24}$

Relatório aponta que na região de Três Lagoas um grupo referido como sendo de Xavante, foi expulso de suas terras por latifundiários. ${ }^{25}$ Situação semelhante ocorreu com diversos povos na área do atual Mato Grosso do Sul. Sobre os Terena, por exemplo, há referências à diminuição de suas áreas e à interferência do poder público nesse processo:

A aldeia Moreira, no município de Miranda, ficou redusida a 57 has. para 78 índios Terenos, sendo que o departamento de Estrada de Rodagem pretende abrir uma estrada com 60 metros de largura cortando essa insignificante propriedade; que as invasões de terra devem ser atribuídas à responsabilidade - dos diversos Prefeitos de Município. Que a área de Limão Verde, também dos Terenos, tem sido invadida, trazendo em desassossego dos próprios índios pela ação dos prefeitos do Município de Aquidauna; que mesmo caso ocorreu na aldeía Passarinho, dos índios Terenos, no Município de Miranda. ${ }^{26}$

\footnotetext{
${ }^{23}$ Ibidem, p. 196.

${ }^{24}$ RELATÓRIO FIGUEIREDO, 1968, v. 20, p. 384.

25 Ibidem, v. 16.

${ }^{26}$ BUCKER, 1967, p. 187.
} 
Os Terena destacam em suas falas que "responsabilizam o Estado brasileiro pelos problemas que enfrentam atualmente: como a diminuição de seu território e a exiguidade de recursos naturais que resultaram em graves dificuldades sociais, políticas e para manutenção de seu modo de vida" 27 Reivindicam, portanto, políticas de reparação, pautadas pela demarcação das terras tradicionalmente ocupadas por eles e que foram tituladas pelo Estado em nome de não indígenas.

\section{a luta dos indígenas pela terra nas páqinas dos jornais}

Tania Regina de Luca explica que as discussões da Escola dos Annales proporcionaram mudanças na concepção daquilo que é considerado documento, com uma ampliação significativa das fontes de pesquisa histórica. Assim foram aceitos como tal desde objetos da cultura material a obras literárias, de séries de dados estatísticos a imagens, de canções aos testamentos, de diários particulares anônimos aos jornais. Essa "revolução documental" ocorreu em conjunto com a necessidade de ampliar a interdisciplinaridade no campo da História. ${ }^{28}$

Apesar dessa renovação impulsionada pelos Annales, Luca destaca que uso dos jornais impressos como fonte de pesquisa até 1970 era visto com desconfiança pela historiografia brasileira. Contudo, a partir dessa mesma década ocorreu um crescimento significativo do uso dos periódicos impressos para o estudo de diferentes objetos de pesquisa. ${ }^{29}$

Alguns critérios são fundamentais no uso das fontes impressas (jornais, revistas, periódicos). Seu uso de maneira indiscriminada, sem metodologia nem aprofundamento teórico, pode trazer sérios problemas para a pesquisa histórica. Como qualquer fonte histórica, os jornais devem ser utílizados criticamente pelo pesquisador, para não correr o risco de deixar-se levar pelo discurso da fonte e, consequentemente, realizar uma análise precipitada, acrítica e superficial.

\footnotetext{
27 XIMENES, 2017, p. 196.
}

28 LUCA, Tania Regina de. Fontes impressas. História dos, nos e por meio dos periódicos. In.: PINSKY, Carla Bassanezi (org.). Fontes históricas. São Paulo: Contexto, 2005.

29 Ibidem. 
Outra recomendação é que não se estude o jornal de maneira isolada. $\bigcirc$ contraponto com outras fontes é fundamental, até porque a análise de um jornal tem uma dupla dimensão: uma que interpreta o texto escrito efetivamente; e outra que precisa abranger aquilo que não aparece escrito, mas é possível identificar à luz do contexto histórico. Assim, o estudo a partir de materiais da imprensa necessita do reconhecimento do que está em torno dela, já que os veículos de comunicação estão invariavelmente atrelados ao seu tempo histórico

Claude-Jean Bertrand alerta que cada vez mais o jornalista, além de construir notícias com as informações, também precisa lutar pela sobrevivência do jornalempresa que, na maioria das vezes, apoia-se no senso comum e na manipulação de estereótipos. ${ }^{30}$

Também é importante conhecer alguns elementos da escrita jornalística. Luca destaca que a manchete e as imagens têm um peso considerável na publicação, já que têm como objetivo chamar a atenção do leitor e ao mesmo tempo fixar um ponto de vista sobre o tema tratado.1.

Mariana Guedes Conde chama a atenção para o lead (texto em letra maior que o corpo do texto e menor que a manchete, colocado próximo a ela) e para a técnica da pirâmide invertida, ou seja, a técnica utilizada em muitos textos jornalísticos que coloca as ideias principais no topo do texto (manchete, lead e primeiros parágrafos). Dessa forma, para a autora: "o lead compõe uma das mais difundidas técnicas de redação jornalística, a pirâmide invertida, que na sua estrutura hierarquiza aspectos de um acontecimento para compor a notícia".32

Em relação à temática indígena, e, mais partícularmente nas questões territoriais, os jornais constituem-se como fontes promissoras. Maria Goretti Leite

30 BERTRAND, Claude-Jean. A deontologia das mídias. São Paulo: EDUSC, 1999.

31 LUCA, op. cit.

32 CONDE, Mariana Guedes. A estrutura do texto jornalístico nas mídia impressa e digital: uma análise do jornal O Globo, oglobo.com e $O$ Globo a Mais. In.: Anais do $4^{\circ}$ Simpósio de Ciberjornalismo. Campo Grande, 2013, p. 5. 
Lima ${ }^{33}$, Patricia Bandeira de Melo34. Priscila Viudes ${ }^{35}$ e Lenir Gomes Ximenes ${ }^{36}{ }^{37}$, são pesquisadoras cujos trabalhos utilizam as fontes da imprensa acerca dos povos indígenas. As ponderações feitas a respeito desse tipo de material devem ser levadas em conta, já que por vezes as representações sobre os povos indígenas nos jornais da grande mídia, são repletas de estereótipos e marcadas pelo preconceito. $O$ diálogo com outras áreas do conhecimento, como a Antropología, auxilia na análise dessas fontes.

Centro de Documentação Indígena Teko Arandu - Cedoc, tem em seu acervo diversas matérias de jornais locais e nacionais a respeito das mobilizações dos povos indígenas para recuperação de suas terras tradicionais no Mato Grosso do Sul. No presente texto foram analisadas duas reportagens sobre ações de Retomada organizadas em 2004, pelos Guarani e Kaiowá, na Terra Indígena Yvy Katu, município de Japorã-MS. Uma delas foi publicada pelo jornal Brasil de Fato (BdF) e a outra pela Folha de São Paulo (Folha).

$\bigcirc$ Brasil de Fato (BdF) é um site de notícias e uma radioagência, além de possuir jornais regionais nos estados do Rio de Janeiro, Minas Gerais, São Paulo, Paraná e Pernambuco. Lançado em 25 de janeiro de 2003, o BdF circulou por mais de dez anos com uma versão impressa nacional. Reúne jornalistas, articulistas e representantes de movimentos populares. A apresentação disponíbilizada no site atribui a esses movimentos populares a sua criação. Destaca ainda que sua linha editorial "entende que na luta por uma sociedade justa e fraterna, a democratização dos meíos de comunicação é fundamental" e acrescenta que o jornal Brasil de Fato tem como missão contribuir no debate de ideias e na análise dos fatos do ponto de vista da necessidade de mudanças sociais no Brasili ${ }^{38}$

O jornal Folha de São Paulo, surgiu em 1 de janeiro de 1960, da fusão de três títulos ("Folha da Manhã", "Folha da Tarde" e "Folha da Noite"). Conforme

\footnotetext{
33 LIMA, Maria Goretti Leite. 0 índio na mídia impressa em Roraima. 2001. 150 f. Dissertação (Mestrado em Multimeios) - Universidade Estadual de Campinas, Campinas, 2001.
}

${ }^{34}$ MELO, Patricia Bandeira de. Sujeitos sem voz: agenda e discurso sobre o índio na mídia em Pernambuco. 213 f. Dissertação (Mestrado em Comunicação), Universidade Federal de Pernambuco, Recife, 2003.

35 VIUDES, P. Índios nas páginas D'O Progresso: representações da desnutrição infantil no jornal. $134 f$. Dissertação (Mestrado em História), Universidade Federal da Grande Dourados, Dourados, 2005.

36 XIMENES, Lenir Gomes. Terra Indígena Buriti: estratégias e performances terena na luta pela terra. 136 f. Dissertação (Mestrado em História), Universidade Federal da Grande Dourados, Dourados, 2011.

37 XIMENES, 2017.

38 BDF. Quem somos. Brasil de Fato, s. n. Disponível em: <https://www.brasildefato.com.br/quemsomos/> . Acesso em: 2 set. 2017. 
informações do seu site, o jornal é atualmente o de maior circulação e representatividade no país, com uma tíragem em torno dos 300 mil exemplares.

\begin{abstract}
Sua missão é produzir informação e análise jornalísticas com credibilidade, transparência, qualidade e agilidade, baseadas nos princípios editoriais do Grupo Folha (independência, espírito crítico, pluralismo e apartidarismo), por meio de um moderno e rentável conglomerado de empresas de comunicação, que contríbua para o aprimoramento da democracia e para a conscientização da cidadania. Tem como visão consolidar-se como o mais influente grupo de mídia do país.39
\end{abstract}

As fotografias utilizadas nas duas matérias são bastante semelhantes, ambas tiradas pelo fotógrafo Lalo de Almeida, colaborador da Folha de São Paulo. Ao fundo, aparece o céu azul com algumas nuvens, contrastando com a silhueta de alguns indígenas próximos a uma cerca de madeira. Um deles está sobre a cerca, usa um cocar e empunha um arco e uma flecha.

A manchete da Folha é "Pintados e armados, índios invadem fazenda". O lead também faz referência às armas que os indígenas estariam portando e identifica as etnias do grupo: "Terra à vista: com espingarda e arco e flecha, 3.000 guaranis e caiuás ocupam 4 propriedades para ampliar a área demarcada". A legenda da imagem é: "Índio armado com arco e flecha e vestido para a guerra fica de guarda na sede da fazenda São Jorge, invadida por guaranis e caiuás" 40

Nos dois primeiros parágrafos o texto menciona o local onde ocorreu a Retomada (denominada novamente como invasão), a quantidade de indígenas envolvidos, destaca que o episódio tería começa em 20 de dezembro e que os Kaíwá e Guarani teriam expulsado oito funcionários das fazendas. No terceiro parágrafo menciona:

39 FOLHA de São Paulo. Quem somos. Folha de São Paulo, s. n. Disponível em: <http://m.folha.uol.com.br/> . Acesso em: 2 set. 2017.

40 CORREA, Hudson. Pintados e armados, índios invadem fazenda. Folha de São Paulo, 04 de janeiro de 2004, s. n. Acervo do Centro de Documentação Indígena Teko Arandu - Cedoc. NEPPI/UCDB. 
Os índios dizem que as fazendas pertencem à terra indígena Yvy Katu. A área demarcada tem 1.600 hectares, mas os índios querem a expansão para 9.461 hectares, o que inclui as fazendas. A região de conflito está próxima à fronteira com o Paraguai. Os índios falam guarani, como os paraguaios, mas são brasileiros.41

Mesmo afirmando que os indígenas são brasileiros, o jornal associa a língua guarani ao Paraguai, sem mencionar que os Guarani e Kaiowá vivem no cone sul desde antes do estabelecimento das fronteiras nacionais.

"Índios armados" é um subtítulo do texto em que a Folha reafirma que os indígenas estão portando armas e ressalta: "todos, incluindo mulheres e crianças, estão 'pintados para a guerra". A fala atríbuída a uma indígena aparece em um box na lateral da página: "Preferimos morrer todos juntos com as crianças. Vivo a gente não sai daqui', disse a índia Cunhã Kãguy, 32, à Agência Folha na sexta-feira"42

A Folha trata como invasão a presença de 3 mil Guarani e Kaiowá em 4 fazendas (que incidem na Terra Indígena) em janeiro de 2004 no município de Japorã. Apresentam em seu texto os indígenas como os pintados para guerra, armados e invasores. Descrevem ao leitor um cenário onde os índios estão dispostos a matar e morrer, usam de violência e são ávidos por mais terras. $\bigcirc$ pecuarista é apresentado como o lado que busca a justiça para resolver a questão fundiáría dentro da lei. ${ }^{43} \bigcirc$ enredo do texto, construído com as falas de ambos os lados, procura levar o leitor a identificar-se com o produtor rural. $\bigcirc$ título e o subtítulo da matéria incentivam o leitor a se posicionar contra os Guarani e Kaiowá.

A Folha evidencia as representações de parte da opinião pública brasileira a respeito das reivindicações territoriais dos povos indígenas, ao mesmo tempo em que contribui para a construção dessas representações.

A manchete do jornal BdF sobre o mesmo episódio é: "Retomadas são recado para presidente". O lead traz: "Guarani e Kaiowá reocupam fazendas em Yvy Katu (terras boas) e denunciam a situação crítica em Mato Grosso do Sul". A legenda da imagem é: "Guarani e Kaiowá retomam suas terras, antes invadidas por fazendeiros,

41 CORREA, 2004, s. n.

42 Ibidem.

43 Ibidem. 
em Japorã (MS)" ${ }^{44}$ Os fazendeiros, e não os indígenas, é que são apresentados como invasores.

No primeiro parágrafo o jornal aponta as razões para a reocupação protagonizada pelos Guarani e Kaiowá:

ano começou com uma dívida histórica a ser paga pelo governo Lula: a demarcação das terras indígenas. Cansados de esperar, desde - dia 20 de dezembro cerca de 3 mil índios das etnias Guarani e Kaiowá decidiram reocupar cinco fazendas em Amabai e Japorã. Mato Grosso do Sul, fronteira com o Paraguai. Para eles, essas são terras yvy katu (terra boa em guarani).45

O jornal demonstra mais familiaridade com as discussões que ocorrem no meio acadêmico, especialmente na área da Antropologia, o que pode ser percebido pela forma como os nomes das etnias são grafados. Diferente da Folha, o BdF utiliza a grafia adotada nos textos antropológicos contemporâneos. Também explicou o significado da expressão em guarani Yvy Katu, que nomeia a Terra Indígena.

Na lateral da página há um box que busca associar o episódio em Japorã a um contexto mais amplo das lutas dos indígenas pelos seus territórios. Nesse texto, o jornal trata do conflito entre indígenas e arrozeiros na terra Indígena Raposa do Sol, em Roraima.

BdF coloca como Retomada a presença dos 3 mil índios nas 4 fazendas em Japorã, que incidem sobre seu território. Justifica a atitude dos indígenas, atribuindo a reocupação à situação insustentável que vivem estas populações, apresenta a ocorrência de suicídios entre os Guarani e Kaiowá como consequência da morosidade do processo de homologação das terras indígenas. $\bigcirc$ texto traz as falas de um antropólogo, de um representante do Conselho Indigenista Missionário CIMI, e do coordenador da Funai.t6

A Folha e o BdF usaram imagens bastante semelhantes, entretanto, o enfoque dado em cada manchete e no próprio texto evidenciam discursos diferentes. Para compreender essa discrepância é fundamental atentar-se para o contexto em que

\footnotetext{
44 JARDIM, Claudia. Retomadas são recado para presidente. Brasil de Fato, 04 de janeiro de 2004, s. n. Acervo do Centro de Documentação Indígena Teko Arandu - Cedoc. NEPPI/UCDB.

45 JARDIM, 2004, s. n.

46 Ibidem.
} 
cada jornal se insere: o BdF ligado a movimentos sociais e a Folha como uma empresa jornalística. Para uma análise mais aprofundada da situação apresentada nas manchetes (a Retomada em Yvy Katu), é fundamental utilizar outras fontes, especialmente orais, com as falas dos próprios indígenas.

episódio descrito na reportagem é objeto de estudo da História e da Antropologia, uma vez que se insere na trajetória histórica das lutas dos Guarani e Kaiowá pelos seus territórios. Alguns elementos apresentados nas matérias (como as pinturas corporais no contexto das Retomadas), podem ser compreendidos a partir da Antropologia.

As fontes da imprensa, como quaisquer outras, podem reproduzir inúmeras representações negativas sobre os povos indígenas, principalmente quando o tema principal é a Retomada de seus territórios tradicionais. Apesar disso, tais fontes evidenciam a atuação dos indígenas e seu papel de sujeitos históricos lutando, negociando e resistindo.

\section{considerações finais}

Para a escrita da História Indígena é importante a utilização de fontes variadas e da interdisciplinaridade. As fontes escritas podem ser analisadas sob uma nova abordagem, evidenciando a participação dos indígenas em diversos processos históricos. Os documentos oficiais, como a documentação do SPI e o Relatório Figueiredo, são exemplos de materiais que fornecem informações importantes sobre a violação de direitos dos indígenas, principalmente em relação aos esbulhos territoriais. Tais fontes devem ser contextualizadas, compreendendo-se as particularidades do tempo e dos órgãos/sujeitos que as produziram.

Os textos jornalísticos fornecem dados importantes sobre as reivindicações territoriais dos indígenas, destacando-se as matérias sobre as Retomadas. Os jornais veiculam diferentes representações, por vezes negativas sobre os povos indígenas e, portanto, é fundamental que o pesquisador contextualize a produção desses textos e tenha cautela para não validar preconceitos e estereótipos veiculados na mídia e perceptíveis inclusive na escolha dos termos utilizados nas manchetes. 